\title{
Relationships Between High Intensity Running and Outcome of Technical-Tactical Skills in Professional Soccer Players During Match Play
}

\author{
Cristoforo Filetti ${ }^{1,5,6}$, Stefano D’Ottavio ${ }^{1,3,6}$, Bruno Ruscello ${ }^{1,4,7}$, Vincenzo Manzi ${ }^{1}$, \\ Wassim Moalla ${ }^{2}$ \\ ${ }^{1}$ Faculty of Medicine and Surgery, School of Sport and Exercise Sciences, University of Rome "Tor Vergata", Rome, Italy \\ ${ }^{2}$ Research Unit EM2S, ISSEP Sfax, Tunisia \\ ${ }^{3}$ FIGC - Federazione Italiana Giuoco Calcio, Florence, Italy \\ ${ }^{4}$ University of Rome "San Raffaele", Rome, Italy \\ ${ }^{5}$ QSL - Qatar Stars League: Football Association, Doha, Qatar \\ ${ }^{6}$ Doctorate School in Advanced Technology in Rehabilitation Medicine and Sports, Cycle XXVII, Faculty of Medicine and Surgery, \\ University of Rome "Tor Vergata”, Rome, Italy \\ ${ }^{7}$ Sport 3.0 Foundation, Bologna, Italy
}

\section{Email address:}

cris.86@hotmail.it (C. Filetti), stefano.dottavio@uniroma2.it (S. D’Ottavio), bruno.ruscello@uniroma2.it (B. Ruscello), vimanzi@yahoo.it(V. Manzi),wassim.moalla@gmail.com (W. Moalla)

\section{To cite this article:}

Cristoforo Filetti, Stefano D’Ottavio, Bruno Ruscello, Vincenzo Manzi, Wassim Moalla. Relationships Between High Intensity Running and Outcome of Technical-Tactical Skills in Professional Soccer Players During Match Play. American Journal of Sports Science.

Vol. 4, No. 1, 2016, pp. 1-9. doi: 10.11648/j.ajss.20160401.11

\begin{abstract}
This study aimed to investigate the relationships between high-intensity activities (HIA: speed, acceleration, Metabolic Power) and the outcomes of some technical-tactical skills in professional soccer players ( $\mathrm{n}=610$, age 26.8 \pm 7.0$)$ during 50 games of the Italian "SERIE A" season 2013-2014. The analysis was carried out through a semi-automatic match analysis video-system. Each technical skill was automatically recognized and the number of events that overcame the threshold values we set as significant for high intensity activities, within $5 \mathrm{~s}$ before the execution. Shots on goal showed that the HIA might be a discriminant factor in the outcomes $\left(71.1 \%\right.$ Success vs $61.5 \%$ Not Success, $\chi^{2}$ test, $\left.p<0.001\right)$. Crossing is clearly influenced by one preceding HIA $(\mathrm{p}<0.001)$. This study provides important insights referring to the different physical components occurring before performing a technical skill, highlighting the need of a close cooperation among coaches and physical trainers when assessing a match and designing the training programs.
\end{abstract}

Keywords: Sprints, Metabolic Power, Skills, Classification Tree, Performance

\section{Introduction}

Performance analysis in football is one of the "new frontiers" that has gained more relevance in the last decade. Many researches have been published to investigate and optimize the performance [1] from a physical and technical tactical point of view. Coaches are often interested to know performance details in the game and to manage all the parameters of the training sessions in order to adapt them each week to the needs of the upcoming opponent as well as the system and the intensity of the game. The concept of high intensity activities (HIA) in soccer is still an argued issue. If over the years the concept has been frequently approached to the domain of speed $[2,3,4]$, quite recently the concept has been increasingly linked to the acceleration domain. In this context, Dwyer and Gabbett [5] proposed a different definition of high intensity, closer to the acceleration concept: "any movement that reaches or exceeds the sprint threshold velocity for at least 1 second and any movement with an acceleration that occurs within the highest 5\% of accelerations found in the corresponding velocity range". Currently the HIA have been seen more and more as a product of the speed by the acceleration, leading to the new concept of Metabolic Power [6, 7]. They suggested a synthesis of all these parameters and proposed an estimate of 
the internal load. Accelerative running is similar to running at constant speed on slope. Knowing the Energetic Cost of running on a slope at constant speed made it possible to hypothesize this new parameter [Metabolic Power: $\mathrm{MP}=\mathrm{C}_{\mathrm{sr}}$ (Energetic Cost) $* \mathrm{v}$ (velocity)].

Applying the Metabolic Power concept to soccer, $43.1 \%$ of the actions are placed in a high intensity zone rather than just the $6.3 \%$ as the speed approach previously reported.

In the last 5 years several papers suggested a strong connection between physical load, especially the HIA, and the technical tactical parameters: Vigne et al. [8] showed that the elite players reduced their amount of distance performed at submaximal speeds and increased the ball possession, while maintaining the high intensity activities.

Likewise, Lago-Penas et al. [9], tried to identify some game related statistics that might explain the causes of winning, drawing and losing in the Spanish soccer league. Their results showed that the winning teams had more total shots, shots on goal, effectiveness, assists, off-sides committed and crosses against.

Deeper is the analysis done by Bradley, Lago-Penas et al. [10] that studied low and high percentage of ball possession, in relation to the physical and technical profiles. They discovered that high intensity with high $\%$ ball possession (HPBP) was 31\% higher than low \% ball possession(LPBP) and $22 \%$ lower without ball possession; furthermore, teams with HPBP performed 44\% more passes than those in LPBP and the same trend is observed for successful passes, received passes, touches for possession, shots, dribbles and final third entries.

Recently the focus in soccer has been oriented to gain more insight into the connection between the high intensity activities and the technical tactical parameters and to study all the variables that allow the designing of training sessions, which ecologically reflects the game intensity found in high level competitions.

The definition of high intensity is often detached from the team sport's real needs. Differently to the performanceoriented individual sports, in team sports one must consider the effective distances to be covered by each player, which may not require the kind of efforts matching the maximal individual capacities, as demonstrated by many researches applying the speed zone approach [2, 3, 4].

With this study we tried to answer some research questions that might be summarized as follows:

- Did the high intensity physical activities, (i.e. running or sprinting over a certain threshold or reaching a certain metabolic power) performed just before executing some technical skill, influence the resulting outcomes (1)?

- Considering a time sampling of 5 seconds $(\mathrm{t}=5 \mathrm{~s})$ prior to the execution of this technical skill, what is the frequency of events that exceed the threshold of highintensity (2)?

The aim of this study was therefore to identify the possible relevance of the high intensity activities on the effectiveness of some technical tactical skill, performed during soccer matches at elite level. The hypothesis we made was that the final outcomes of the technical tactical skills we investigated were influenced by the occurrence of High Intensity Activities performed within a 5 seconds time interval prior to the execution of the skills.

\section{Methods}

\subsection{Participants}

Six hundred and ten elite players $(n=610)$ took part in this study (age 26.8 \pm 7.0 , height $1.82 \pm 0.5 \mathrm{~m}$, weight $76 \pm 7 \mathrm{Kg}$ ). Fifty matches $(\mathrm{n}=50)$, out of 380 , of the Italian premier soccer league - "Serie A" - season 2013-2014 were randomly selected for this study. The Institutional Research Board (University of Rome "Tor Vergata", Faculty of Medicine Ethical Committee) provided clearance for the procedures before the commencement of this study. All procedures were carried out in accordance with the Declaration of Helsinki of the World Medical Association as regards the conduct of clinical research.

\subsection{Research Design}

In this study, to investigate the relationship between the physical performance (i.e. running), occurring during the game and reaching or exceeding a threshold, we set as indicative of the high intensity events (independent variables: speed, acceleration and metabolic power) just before performing (i.e. within 5 seconds) some technical skill, whose final outcome - achieving or not a positive result was set as a dependent dichotomy variable. We considered as major technical skills the shots, the crosses, the forward passes, the dribbling, the interceptions and the tackles that we recorded during some of the soccer matches played at elite level.

We applied the thresholds (very high intensity) as by Osgnach et al. [7] publication:

- Speed: $\mathrm{v}>6 \mathrm{~m} \cdot \mathrm{s}^{-1}$

- Acceleration (positive and negative): $\mathrm{a}>|3| \mathrm{m} \cdot \mathrm{s}^{-2}$

- Metabolic Power (MP): $\mathrm{P}>55 \mathrm{~W} \cdot \mathrm{Kg}^{-1}$

The high intensity events, occurring within 5 seconds prior to the execution of the selected skills that reached the above mentioned thresholds were then computed as absolute frequencies. This time interval of $5 \mathrm{~s}$ was arbitrary chosen by the authors according to their personal experiences as international soccer coaches. In order to define this time interval, we took into account the average 1300 variations of velocity per game [8], dividing the match total time (5400 s, that is $5400 \mathrm{~s} / 1300$ variations is equal to roughly $4.1 \mathrm{~s}$ each event). Through an inferential statistical analysis we explored the relationship and the relevance between the technical effectiveness (the outcomes) and the occurrence (or not) of such high intensity activities. The considered technical skills, along with the definitions of successful (S) and not successful (NS) outcome, were defined as follows, as suggested by the Prozone user's manual:

I. In possession skills 
Forward passes: only passes with forward direction in the offensive half field with significant peripheral density (number of opponents and teammates, game spaces). Successful when the teammate receives the ball, not successful if ball goes out or is captured by the opponent.

Shots and header shots: attempts on goal considering successful when they go on target and not successful when the attempt is blocked or the ball goes out.

Crosses: it is considered that only the translocation of the ball, in the final third, from a lateral area (right or left zones of final third) to the central area: successful if the ball reaches the central part of final third, not successful if the ball goes out or reaches the opposite third field.

Dribbling: event in which a player in possession of the ball dribbles an opponent, keep possession and gaining an advantage for the team. Not successful if the attempt to dribble results in the loss of possession.

\section{Without possession skills}

Interceptions: when a player stops the transmission of the ball between two opponents, successful when retains possession or the ball goes out, not successful if the ball is back in the possession of the opponents.

Tackles: a duel to regain possession of the ball from an opponent; successful if the recapture occurs, not successful if the ball remains in possession of the opponent.

\subsection{Instrumentation}

All the video data were collected by K-Sport Tracking Semi-Automatic System \& AMISCO Pro Tracking System (Prozone Sport, Leeds, UK) and processed by K-Sport online (K-Sport, Montelabbate, PU, Italy). The time intervals required to be considered over threshold for each parameter were:

- 1 second for speed

- 0.4 second for acceleration

- 0.4 second for metabolic power

\subsection{Procedures}

All the data were collected at the end of the season 20132014 and the process involved one single observer who selected each single technical skill, according to the operational guidelines above mentioned. After this first selection phase, we analyzed all the physical events (i.e. running) occurred in this 5 seconds considered time frame, assigning each of them to the pre designed thresholds of specific intensity and then computing the relevant occurrences.

\subsection{Statistical Analysis}

The assumption of normality was assessed using the Shapiro-Wilk test. Data are presented as absolute and relative frequencies (n; \%). Parametric and nonparametric statistics were used when appropriate. The Chi square test was performed to find the possible differences in distribution among the selected independent variables, in relation to the possible outcomes.

In order to verify the hypothesis we made, a binary logistic regression analysis was also performed, to assess whether the four predictor variables significantly explain the different binomial outcomes we observed.

Odds ratio (OR) values were also computed to quantify how strongly the presence or absence of property A (the high intensity parameters) is associated with the presence or absence of property B (the positive or negative outcomes of these specific technical skills).

A Classification Tree Analysis [11], applying a Chisquared Automatic Interaction Detection [12], was also performed in order to verify the influence of the different expression of the independent variables (number of events), on the dependent one we considered (positive-negative outcome).

The corresponding $\mathrm{P}$ values are provided for each analysis. The value of statistical significance was accepted with $\mathrm{P}<$ 0.05. IBM SPSS 20 for Windows (SPSS Inc., Chicago, IL) was used to analyze and process the collected data.

\section{Results}

The relevant statistics provided divides the analysis into "in possession skills" and "without possession skills".

\section{In possession skills}

In this section we provide the processed data and the statistics referring to the "in possession skills", as descriptive statistics (table 1) and chi square test (table 2).

Table 1. In possession skills: Shots on goal ( $n=1395)$; dribbles $(n=840)$; crosses $(n=1429)$; forward passes ( $n=15277) ;$ high intensity events (\%) recorded within the 5 s time sampling considered, prior to the performance.

\begin{tabular}{lllll|l}
\hline skill & $\mathbf{n}$ & Speed (\%) & Positive Acc. (\%) & Negative Acc. (\%) \\
\hline & 0 & 63.2 & 51.5 & 54.6 & Metabolic Power (\%) \\
& 1 & 28.0 & 32.0 & 33.3 & 9.3 \\
& 2 & 7.1 & 11.2 & 1.6 & 34.3 \\
& 3 & 1.1 & 3,9 & 1.2 & 35.9 \\
Shots on goal & 4 & 0.5 & 1.3 & - & 15.6 \\
& 5 & 0.2 & 0.1 & 100.0 & 10.0 \\
& 6 & - & - & 70.1 & 3.4 \\
& Total & 100.0 & 100.0 & 26.8 & 0.2 \\
& 0 & 77.4 & 67.9 & 3.1 & 0.6 \\
dribbles & 1 & 19.0 & 27.4 & - & 100.0 \\
& 2 & 3.6 & 4.8 & 100.0 \\
\hline
\end{tabular}




\begin{tabular}{llllll}
\hline skill & n & Speed (\%) & Positive Acc. (\%) & Negative Acc. (\%) & Metabolic Power (\%) \\
\hline \multirow{4}{*}{ crosses } & 0 & 46.2 & 49.2 & 42.3 & 23.9 \\
& 1 & 44.4 & 36.0 & 42.2 & 41.2 \\
& 2 & 7.6 & 11.3 & 13.6 & 17.6 \\
& 3 & 1.8 & 2.4 & 1.8 & 11.3 \\
& 4 & - & 1.0 & 0.1 & 4.9 \\
& 5 & - & 0.1 & - & 1.1 \\
& 6 & - & - & - & 0.1 \\
Forward passes & Total & 100.0 & 100.0 & 100.0 & 100.0 \\
& 0 & 88.5 & 75.6 & 80.4 & 73.0 \\
& 1 & 10.5 & 22.6 & 17.1 & 20.9 \\
& 2 & 0.9 & 1.8 & 2.4 & 5.2 \\
& 3 & 0.1 & - & 0.1 & 0.8 \\
\hline
\end{tabular}

Table 2. In possession skills: Shots on goal ( $n=1395)$; dribbles $(n=840)$; crosses $(n=1429)$; forward passes $(n=15277)$; high intensities events $(\%)$ recorded within the 5s time sampling considered, prior to the performance, according to the final outcome: $S=$ successful; NS= not successful.

\begin{tabular}{|c|c|c|c|c|c|c|c|c|c|}
\hline \multirow[t]{2}{*}{ skill } & \multicolumn{3}{|c|}{ Speed $(\%)$} & \multicolumn{6}{|c|}{ Positive Acceleration (\%) } \\
\hline & n & $\mathbf{S}$ & NS & $\Delta|\mathbf{S}-\mathbf{N S}|$ & $\mathbf{P}^{*}\left(\chi^{2}\right)$ & $\mathbf{S}$ & NS & $\Delta|\mathbf{S}-\mathbf{N S}|$ & $\mathbf{P}^{*}\left(\chi^{2}\right)$ \\
\hline \multirow{7}{*}{$\begin{array}{l}\text { Shots on goal }(S=615 ; \\
N S=780)\end{array}$} & 0 & 58.7 & 66.7 & $|8.0|$ & 0.00 & 47.0 & 55.1 & $|8.1|$ & 0.00 \\
\hline & 1 & 30.9 & 25.6 & $|5.3|$ & 0.61 & 27.2 & 35.9 & $|8.7|$ & 0.00 \\
\hline & 2 & 8.0 & 6.4 & $|1.6|$ & 0.92 & 14.0 & 9.0 & $|5.0|$ & 0.20 \\
\hline & 3 & 0.8 & 1.3 & $|0.5|$ & 0.20 & 8.8 & - & $|8.8|$ & - \\
\hline & 4 & 1.1 & - & $|1.1|$ & - & 2.9 & - & $|2.9|$ & - \\
\hline & 5 & 0.5 & - & $|0.5|$ & - & 0.2 & - & $|0.2|$ & - \\
\hline & Total & 100.0 & 100.0 & - & - & 100.0 & 100.0 & - & - \\
\hline \multirow{5}{*}{ Dribbles $(S=450 ; \mathrm{NS}=390)$} & 0 & 84.6 & 71.1 & $|7.5|$ & 0.69 & 61.5 & 73.2 & $|11.7|$ & 0.00 \\
\hline & 1 & 15.4 & 22.2 & $|6.8|$ & 0.00 & 33.3 & 22.2 & $|11.1|$ & 0.05 \\
\hline & 2 & - & 6.7 & $|6.7|$ & - & 5.1 & 4.4 & $|0.7|$ & 1.00 \\
\hline & 3 & - & - & - & - & - & - & - & - \\
\hline & Total & 100.0 & 100.0 & - & - & 100.0 & 100.0 & - & - \\
\hline \multirow{8}{*}{ Crosses $(\mathrm{S}=1058 ; \mathrm{NS}=371)$} & 0 & 44.1 & 52.0 & $|7.9|$ & 0.00 & 48.5 & 51.2 & $|2.7|$ & 0.00 \\
\hline & 1 & 46.1 & 39.4 & $|6.7|$ & 0.00 & 37.7 & 31.0 & $|6.7|$ & 0.00 \\
\hline & 2 & 7.6 & 7.8 & $|0.2|$ & 0.00 & 10.3 & 14.0 & $|3.7|$ & 0.00 \\
\hline & 3 & 2.2 & 0.8 & $|1.4|$ & 0.00 & 2.9 & 1.1 & $|1.8|$ & 0.00 \\
\hline & 4 & - & - & - & - & 0.5 & 2.7 & $|2.2|$ & 0.20 \\
\hline & 5 & - & - & - & - & 0.1 & - & $|0.1|$ & - \\
\hline & 6 & - & - & - & - & - & - & - & - \\
\hline & Total & 100.0 & 100.0 & - & - & 100.0 & 100.0 & - & - \\
\hline \multirow{6}{*}{$\begin{array}{l}\text { Forward Passes }(\mathrm{S}=9958 \\
\mathrm{NS}=5319) \mathrm{MP}, \mathrm{NS}=5306\end{array}$} & 0 & 89.3 & 87.1 & $|2.2|$ & 0.00 & 77.3 & 72.5 & $|4.8|$ & 0.00 \\
\hline & 1 & 9.9 & 11.4 & $|1.5|$ & 0.00 & 20.7 & 26.1 & $|5.4|$ & 0.00 \\
\hline & 2 & 0.6 & 1.4 & $|0.8|$ & 0.27 & 2.0 & 1.4 & $|0.6|$ & 0.00 \\
\hline & 3 & 0.1 & - & $|0.1|$ & - & - & - & - & - \\
\hline & 4 & - & - & - & - & - & - & - & - \\
\hline & Total & 100.0 & 100.0 & - & - & 100.0 & 100.0 & - & - \\
\hline
\end{tabular}

Table 2. Continued.

\begin{tabular}{|c|c|c|c|c|c|c|c|c|c|}
\hline \multirow[t]{2}{*}{ skill } & \multirow[b]{2}{*}{$\mathbf{n}$} & \multicolumn{4}{|c|}{ Negative Acceleration (\%) } & \multicolumn{3}{|c|}{ Metabolic Power (\%) } & \multirow[b]{2}{*}{$\mathbf{P}^{*}\left(\chi^{2}\right)$} \\
\hline & & $\mathbf{S}$ & NS & $\Delta|\mathbf{S}-\mathbf{N S}|$ & $\mathbf{P}^{*}\left(\chi^{2}\right)$ & $\mathbf{S}$ & NS & $\Delta|\mathbf{S}-\mathbf{N S}|$ & \\
\hline \multirow{7}{*}{$\begin{array}{l}\text { Shots on goal }(S=615 \\
N S=780)\end{array}$} & 0 & 45.7 & 61.5 & $|15.8|$ & 0.00 & 28.9 & 38.5 & $|9.6|$ & 0.00 \\
\hline & 1 & 39.8 & 28.2 & $|11.6|$ & 0.25 & 34.0 & 37.4 & $|3.4|$ & 0.00 \\
\hline & 2 & 9.3 & 9.4 & $|0.1|$ & 0.16 & 18.2 & 13.6 & $|4.6|$ & 0.68 \\
\hline & 3 & 2.4 & 0.9 & $|1.5|$ & 0.09 & 11.9 & 8.5 & $|3.4|$ & 0.55 \\
\hline & 4 & 2.8 & - & $|2.8|$ & - & 5.0 & 2.1 & $|2.9|$ & 0.03 \\
\hline & 5 & - & - & - & - & 0.5 & - & $|0.5|$ & - \\
\hline & Total & 100.0 & 100.0 & - & - & 100.0 & 100.0 & - & - \\
\hline \multirow{5}{*}{ Dribbles $(S=450 ; N S=390)$} & 0 & 62.2 & 76.7 & $|14.5|$ & 0.00 & 53.3 & 50.7 & $|2.6|$ & 0.34 \\
\hline & 1 & 33.3 & 21.1 & $|12.2|$ & 0.02 & 26.9 & 36.7 & $|9.8|$ & 0.00 \\
\hline & 2 & 4.1 & 2.2 & $|1.9|$ & 0.24 & 16.9 & 11.1 & $|5.8|$ & 0.14 \\
\hline & 3 & - & - & - & - & 2.8 & 1.6 & $|1.2|$ & 0.35 \\
\hline & Total & 100.0 & 100.0 & - & - & 100.0 & 100.0 & - & - \\
\hline \multirow{4}{*}{ Crosses $(S=1058 ; \mathrm{NS}=371)$} & 0 & 40.4 & 48.0 & $|7.6|$ & 0.00 & 22.4 & 28.0 & $|5.6|$ & 0.00 \\
\hline & 1 & 41.7 & 43.7 & $|2.0|$ & 0.00 & 41.5 & 40.4 & $|1.1|$ & 0.00 \\
\hline & 2 & 16.9 & 4.0 & $|12.9|$ & 0.00 & 16.3 & 21.3 & $|5.0|$ & 0.00 \\
\hline & 3 & 0.9 & 4.3 & $|3.4|$ & 0.24 & 13.4 & 5.1 & $|8.3|$ & 0.00 \\
\hline
\end{tabular}




\begin{tabular}{|c|c|c|c|c|c|c|c|c|c|}
\hline \multirow[t]{2}{*}{ skill } & \multirow[b]{2}{*}{$\mathbf{n}$} & \multicolumn{4}{|c|}{ Negative Acceleration (\%) } & \multicolumn{3}{|c|}{ Metabolic Power (\%) } & \multirow[b]{2}{*}{$\mathbf{P}^{*}\left(\chi^{2}\right)$} \\
\hline & & $\mathbf{S}$ & NS & $\Delta|\mathbf{S}-\mathbf{N S}|$ & $\mathbf{P}^{*}\left(\chi^{2}\right)$ & $\mathbf{S}$ & NS & $\Delta|\mathbf{S}-\mathbf{N S}|$ & \\
\hline \multirow{10}{*}{$\begin{array}{l}\text { Forward Passes }(\mathrm{S}=9958 \\
\mathrm{NS}=5319) \mathrm{MP}, \mathrm{NS}=5306\end{array}$} & 4 & 0.1 & - & $|0.1|$ & - & 5.0 & 4.6 & $|0.4|$ & 0.00 \\
\hline & 5 & - & - & - & - & 1.3 & 0.5 & $|0.8|$ & 0.00 \\
\hline & 6 & - & - & - & - & 0.1 & - & - & - \\
\hline & Total & 100.0 & 100.0 & - & - & 100.0 & 100.0 & - & - \\
\hline & 0 & 82.7 & 76.0 & $|6.7|$ & 0.00 & 73.8 & 71.6 & $|2.2|$ & 0.00 \\
\hline & 1 & 14.7 & 21.7 & $|7.0|$ & 0.00 & 20.0 & 22.5 & $|2.5|$ & 0.00 \\
\hline & 2 & 2.5 & 2.3 & $|0.2|$ & 0.00 & 5.4 & 5.0 & $|0.4|$ & 0.00 \\
\hline & 3 & 0.1 & - & $|0.1|$ & - & 0.8 & 0.8 & $|0.0|$ & 0.00 \\
\hline & 4 & - & - & - & - & 0.1 & 0.1 & $|0.0|$ & 1.00 \\
\hline & Total & 100.0 & 100.0 & - & - & 100.0 & 100.0 & - & - \\
\hline
\end{tabular}

\section{Without possession skills}

In this section we provide the processed data referring to the "without possession skills", as descriptive statistics (table 3) and chi square test (table 4).

Table 3. Without possession skills: interception ( $n=4350)$; tackles $(n=2491)$ : high intensities events $(\%)$ recorded within the 5 s time sampling considered, prior to the performance.

\begin{tabular}{|c|c|c|c|c|c|}
\hline skill & $\mathbf{n}$ & Speed (\%) & Positive Acc. (\%) & Negative Acc. (\%) & Metabolic Power (\%) \\
\hline \multirow{6}{*}{ Interceptions } & 0 & 86.9 & 75.8 & 76.1 & 71.7 \\
\hline & 1 & 11.7 & 20.9 & 20.4 & 21.9 \\
\hline & 2 & 1.4 & 3.1 & 3.3 & 5.9 \\
\hline & 3 & - & 0.2 & 0.2 & 0.5 \\
\hline & 4 & - & - & - & 0.2 \\
\hline & Total & 100.0 & 100.0 & 100.0 & 100.0 \\
\hline \multirow{4}{*}{ Tackles } & 0 & 89.6 & 69.9 & 77.7 & 65.5 \\
\hline & 2 & 0.0 & 2.6 & 2.1 & 4.0 \\
\hline & 3 & - & - & - & 0.4 \\
\hline & Total & 100.0 & 100.0 & 100.0 & 100.0 \\
\hline
\end{tabular}

Table 4. Without possession skills: Interception ( $n=4350)$; Tackles ( $n=2430)$ : high intensities events (\%) recorded within the 5s time sampling considered, prior to the performance, according to the outcome: $S=$ successful; $N S=$ not successful.

\begin{tabular}{|c|c|c|c|c|c|c|c|c|c|}
\hline \multirow[t]{2}{*}{ skill } & \multicolumn{3}{|c|}{ Speed (\%) } & \multicolumn{6}{|c|}{ Positive Acceleration (\%) } \\
\hline & $\mathbf{n}$ & $\mathbf{S}$ & NS & $\Delta|\mathbf{S}-\mathbf{N S}|$ & $\mathbf{P}^{*}\left(\chi^{2}\right)$ & $\mathbf{S}$ & NS & $\Delta|\mathbf{S}-\mathbf{N S}|$ & $\mathbf{P}^{*}\left(\chi^{2}\right)$ \\
\hline \multirow{6}{*}{$\begin{array}{l}\text { Interceptions } \\
(S=1460 ; N S=2890)\end{array}$} & 0 & 85.6 & 87.5 & $|1.9|$ & 0.00 & 78.6 & 74.4 & $|4.2|$ & 0.00 \\
\hline & 1 & 13.7 & 10.7 & $|3.0|$ & 0.00 & 18.6 & 22.1 & $|3.5|$ & 0.00 \\
\hline & 2 & 0.7 & 1.7 & $|1.0|$ & 0.00 & 2.7 & 3.3 & $|0.6|$ & 0.00 \\
\hline & 3 & - & - & - & - & - & 0.2 & $|0.2|$ & - \\
\hline & 4 & - & - & - & - & - & - & - & - \\
\hline & total & 100.0 & 100.0 & - & - & 100.0 & 100.0 & - & - \\
\hline \multirow{4}{*}{$\begin{array}{l}\text { Tackles } \\
(\mathrm{S}=860 ; \mathrm{NS}=1630)\end{array}$} & 1 & 11.5 & 9.8 & $|1.7|$ & 0.00 & 26.3 & 28.2 & $|1.9|$ & 0.00 \\
\hline & 2 & 0.1 & - & $|0.1|$ & - & 4.0 & 1.8 & $|2.2|$ & 0.62 \\
\hline & 3 & - & - & - & - & - & - & - & - \\
\hline & total & 100.0 & 100.0 & - & - & 100.0 & 100.0 & - & - \\
\hline
\end{tabular}

Table 4. Continued.

\begin{tabular}{|c|c|c|c|c|c|c|c|c|c|}
\hline \multirow[t]{2}{*}{ skill } & \multirow[b]{2}{*}{$\mathbf{n}$} & \multicolumn{4}{|c|}{ Negative Acceleration (\%) } & \multicolumn{3}{|c|}{ Metabolic Power (\%) } & \multirow[b]{2}{*}{$\mathbf{P}^{*}\left(\chi^{2}\right)$} \\
\hline & & $\mathbf{S}$ & NS & $\Delta|\mathbf{S}-\mathbf{N S}|$ & $\mathbf{P}^{*}\left(\chi^{2}\right)$ & $\mathbf{S}$ & NS & $\Delta|\mathbf{S}-\mathbf{N S}|$ & \\
\hline \multirow{6}{*}{$\begin{array}{l}\text { Interceptions } \\
(S=1460 ; N S=2890)\end{array}$} & 0 & 76.2 & 76.0 & $|0.2|$ & 0.00 & 76.5 & 69.2 & $|7.3|$ & 0.00 \\
\hline & 1 & 20.2 & 20.5 & $|0.3|$ & 0.00 & 19.4 & 23.1 & $|3.7|$ & 0.00 \\
\hline & 2 & 3.6 & 3.2 & $|0.4|$ & 0.00 & 3.5 & 7.1 & $|3.6|$ & 0.00 \\
\hline & 3 & - & 0.3 & $|0.3|$ & - & 0.1 & 0.6 & $|0.5|$ & - \\
\hline & 4 & - & - & - & - & 0.5 & - & $|0.5|$ & - \\
\hline & total & 100.0 & 100.0 & - & - & 100.0 & 100.0 & - & - \\
\hline \multirow{4}{*}{$\begin{array}{l}\text { Tackles } \\
(\mathrm{S}=860 ; \mathrm{NS}=1630)\end{array}$} & 1 & 20.1 & 20.2 & $|0.1|$ & 0.00 & 27.6 & 34.8 & $|7.2|$ & 0.00 \\
\hline & 2 & 0.2 & 3.1 & $|2.9|$ & 0.00 & 5.5 & 1.2 & $|4.3|$ & 0.00 \\
\hline & 3 & - & - & - & - & 0.6 & - & $|0.6|$ & - \\
\hline & total & 100.0 & 100.0 & - & - & 100.0 & 100.0 & - & - \\
\hline
\end{tabular}

Furthermore, exploring deeper the relationship between S and NS and their specific significance, we provide the relevant outcomes of the binary logistic regression (table 5). 
Table 5. Logistic Binary Regression Analysis: this summary table shows the results obtained by relating the number of the physical events performed at high intensity, in the 5 seconds preceding the execution of the considered technical skills (independent variables) and their final outcome (dependent variable).

\begin{tabular}{lllll}
\hline Variables (ne) & $\boldsymbol{\beta}$ & $\boldsymbol{S E}$ & Odds ratio & $\boldsymbol{P}$ \\
\hline Speed & - & - & - & - \\
Positive Acceleration (Shots on goal) & 0,40 & 0,08 & 1,49 & 0,00 \\
Negative Acceleration (Dribbling) & 0,92 & 0,17 & 2,50 & 0,00 \\
Metabolic Power (Crosses) & 0,209 & 0,076 & 1,232 & 0,006 \\
\hline
\end{tabular}

As an example, we provide the clearest CT analysis, regarding the shots on goal, which shows the positive acceleration behavior before this technical skill.

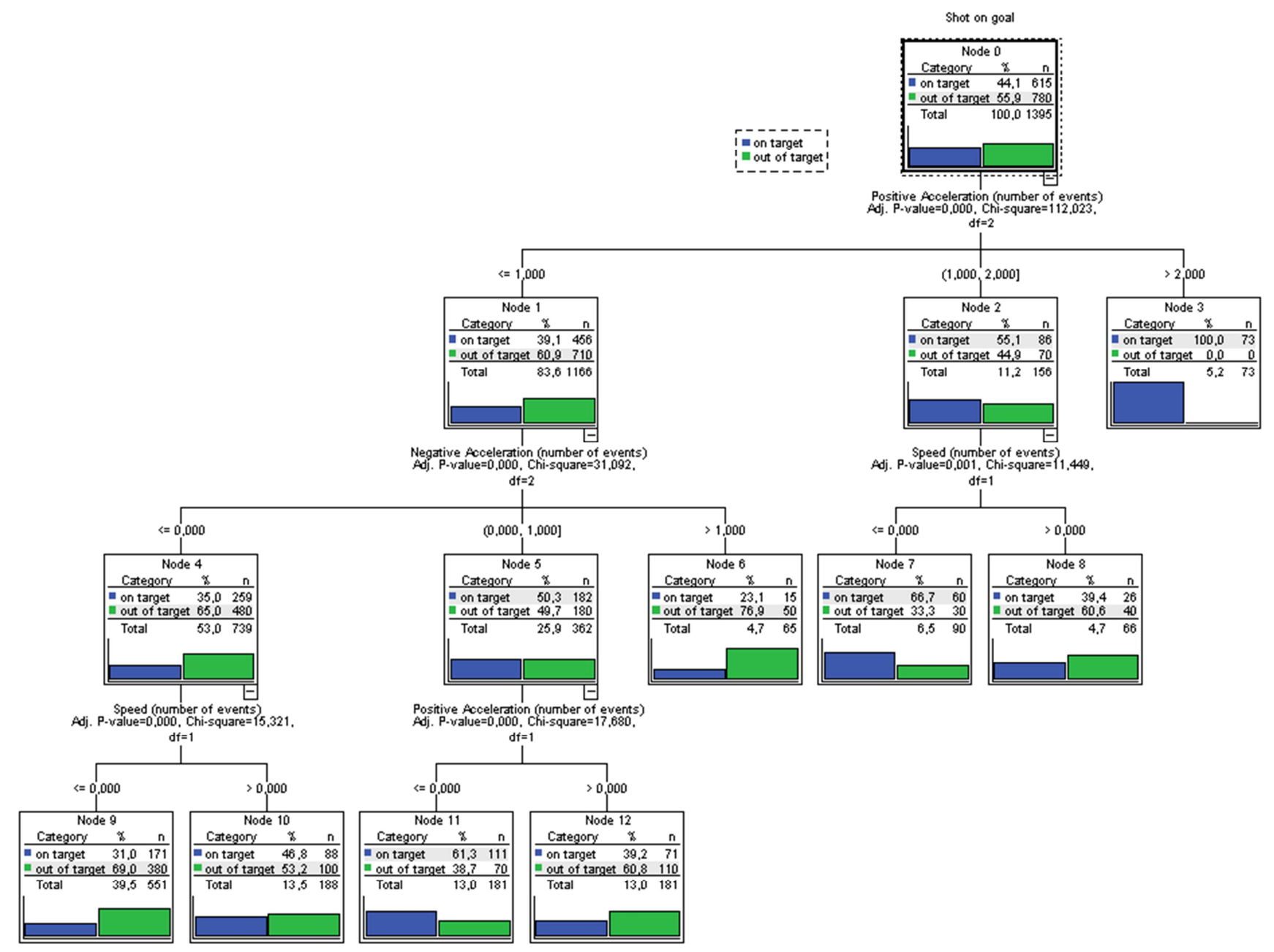

Figure 1. Classification tree analysis: shots on goal details.

\section{Discussion}

To our knowledge, this is the first study investigating the relationship between the high intensity running and outcome of technical tactical skills in professional soccer players considering a time frame of 5 seconds prior to the execution of those skills.

The hypothesis we made was that the final results of those skills (successful or not) were influenced by the occurrence of high intensity activities (HIA) in this specific time frame. In order to do so, we applied a video match analysis procedure able to detect the relevant parameters (speed, acceleration, Metabolic Power) when exceeding the thresholds set according to specific time intervals. In details, the parameters analyzed, showed the following findings:

Shots: as we can see in Table I, the overall results highlighted a distribution, not considering the final result (successful or not successful), that seems to emphasize the low - medium intensity before the skill execution $(n=0)$ for speed $(63.2 \%)$ and acceleration (positive $51.5 \%$ and negative $54.6 \%$ ). Conversely we found an inverse trend when using the Metabolic Power as the measure: indeed $65.7 \%$ of the events showed high intensity MP before the skill with a $51.5 \%$ between one and two events.

In Table II we observed that the over-threshold events were divided in 615 events $(44.1 \%)$ that were S and 780 events $(55.9 \%)$ that were NS. Looking at the high intensity 
speed, we found that the $58.7 \%$ of the successful events occurred without prior high intensity as well as $66.7 \%$ of the not successful events; this difference was statistically significant $(\mathrm{p}<0.001)$.

The binary logistic regression and the classification tree (CT) analysis (Figure I) showed (CHAID; $<<0.0001)$ that the positive acceleration might be important $(\mathrm{S}=53 \%)$ for the success of the shot with at least one over-threshold event $\left(\mathrm{a}>3 \mathrm{~m} \cdot \mathrm{s}^{-2}\right)$, but not crucial for the success of the skill ( $\mathrm{NS}=44.9 \%$ ). It is interesting to note as with 3 or more accelerations before the shot, this skill achieved a $100 \%$ success $\left(\chi^{2}=112.023 ; \mathrm{df}=2 ; \mathrm{p}<0.0001\right)$, even if this condition is present only for $n=73$ events (i.e. $5.2 \%$, CT node 1 , events of positive acceleration $>2$ ). These findings could be in agreement with what was found, in other team sports [13]. Some authors divulgated that using a sport-specific skills task, participants were able to use some self-control strategies to optimize the performances when fatigued and any decline in cognitive performance was minimal. The metabolic power showed a $65.7 \%$ of events with at least one previous high intensity event and a significant difference $(p<0.0001)$ between successful events $(S=34.0 \%)$ and not successful (NS=37.4\%). This data could support the Di Prampero's [6] Isopower concept in soccer.

Dribbling is a widely investigated parameter $[14,15]$, especially in the talent research field as a key performance indicator (KPI) to assess the technical capacities of the young soccer players. As shown in Table I, the skill to "dribble" an opponent finds that a majority of the preceding physical events are at low intensity (speed with zero events over threshold $=77.4 \%$, positive acceleration $=67.9 \%$, negative acceleration $=70.1 \%$ ). Furthermore, a significant difference $(p<0.001)$ emerges by $\mathrm{S}$ and NS outcomes in relation to at least one high intensity event before the dribbling for positive $(\mathrm{S}=61.5 \%$ vs $73.2 \%$ ) and negative ( $\mathrm{S}=62.2 \%$ vs $76.7 \%$ ) acceleration respectively (table II). The binary logistic regression and the $\mathrm{CT}$ analysis we made confirmed that the dribbling does not require high intensity for the success: the exception was the $31.6 \%$ of the events with one previous over-threshold event $(\mathrm{p}<0.001)$ for negative acceleration.

Some authors $[16,17,18]$ suggested that the dribbling ability is position specific and it cannot be solely related to the physical capacities; nevertheless young players (U14) with good dribbling abilities are more likely to be selected to play as midfielders and then this ability is considered purely technical. Our findings seem to confirm it.

Likewise Huijgen et al. [19], published a paper that divulgated that dribbling ability is a real important parameter for the talent selection and they found differences between elite and sub-elite: players that achieved an elite level seem to perform faster dribbling than the sub-elite ones; no clear notes are reported to clarify which physical parameters really affect this skill. Our findings might give more information on that, since our investigation aimed at assessing what was happening just before the performance (within $5 \mathrm{~s}$ ).

Crossing. The analysis we performed (table I) suggests that the final outcome is independent from the physical events occurring prior the performance $(46.2 \%$ with speed $=0$ vs $53.8 \%$ with speed $\geq 1,49.2 \%$ with positive acceleration $=0$ vs $50.8 \%$ positive acceleration $\geq 1,42.3 \%$ with negative acceleration $=0$ vs 57.7 with negative acceleration $\geq 1$ ). The Metabolic Power is the parameter that clearly gives the most relevant information: a $76.1 \%$ of the crosses occurred with at least one Metabolic Power event over the set threshold.

This trend is confirmed by the S/NS analysis (table II) where a substantial balance between ne $=0$ and ne $\geq 1$ emerges; nevertheless performing one high intensity event before this technical skill is a discriminating factor for the outcome ( speed $=46.1 \%$ vs $39.4 \%, \mathrm{p}<0.001$; positive acceleration= $37.7 \%$ vs $31.0 \%, \mathrm{p}<0.001$; negative acceleration $=41.7$ vs $43.7 \%, p<0.001$; metabolic power $=41.5 \%$ vs $40.4 \%$, $\mathrm{p}<0.001)$. The Binary logistic regression and the CT analysis we conducted emphasized the relevance of the HIA Metabolic Power events on the final outcomes prior to the cross (CHAID; $p<0.0001$ ), especially when the high intensity actions were 2 or 3 within the temporal frame we considered $\left(\chi^{2}=25.629 ; \mathrm{df}=3 ; \mathrm{p}<0.0001\right)$. Our findings seem to strongly support what suggested by Bradley et al. [10].

Passing. This skill is the parameter that showed the clearest evidences: a big sample was analyzed $(n=15277)$ and this skill was performed most of the time $(88.5 \%, 75.6 \%$, $80.4 \%$, and $73.0 \%$ for speed, positive and negative acceleration and Metabolic Power, respectively) without preceding high intensity events, in any form (tables I and II). Even the binary logistic regression and the CT analysis we performed, showed how the HIA before any pass would not affect consistently the outcome, in agreement to Seif-Barghi et al. [20], who studied this ability in futsal and in agreement with Vilar et al.[13], who studied this ability in soccer. They demonstrated, respectively, that successful soccer passing might be enhanced by mental imagery or by the visual spatial skills, representing all together the cognitive side of the game.

The Interceptions and the Tackles (table III) we analyzed emphasized that they mostly occurred without previous high intensity events. Even considering the success or not success of these performances (tables IV), we noted how speed, acceleration (positive or negative) and Metabolic Power have often low occurrences over the considered thresholds.

Interception. This has been considered as an individual tactical skill and its efficacy on the defensive phase seems to depend on experience the most [21].

Tackle. This is a very complex technical skill and its success may rely greater on the fine timing ability during the whole intervention, more than the expression of pure physical capacities; if the timing is wrong it could be a great risk for the team and for the health of the opponent [22].

Our analysis, the binary logistic regression and the CT analysis, seem to align with the above mentioned considerations, confirming the priority of technique over any other physical dimension.

Limitations of the study are relative to the domestic dimension of the games we analyzed, although of a top level (Italian "Serie A"). The authors suggest possible influences 
of the different competing styles adopted in different countries. Furthermore, we considered only the "ball zone" in that instant for each event, not considering what is going on all the entire pitch.

\section{Conclusions}

The main suggestion that this study provides is in relation to how the elite soccer performance should be analyzed. Indeed it seems that it is not completely correct to analyze the physical performance detached from the technical skills that are used to solve the tactical situations and therefore from the game ecological context.

For example, the efficacy of some specific training means, such as the small sided games, seems to be in doubt, especially the one known as SSG with small side pitch and high density. The latter emphasizes the sprint ability (positive and negative accelerations and changes of direction [23, 24]) and then the specific energetic cost of these skills, although we have to report the doubts of some recent paper, about the physical load and the connection with the performance in elite soccer, when the SSGs are considered as a part of the specific training program [10]. It highlights that maybe the SSGs do not provide the needed and specific "tactical stimulus" when the technical skills (when in possession the most) are only partially considered.

Our findings, in answer to our first question (1), showed that the shots on goal are strongly influenced by the high intensity Metabolic Power and moderate one for the positive acceleration (ne $\geq 1$ ) before the impact with the ball. Likewise the crosses success seemed to be independent from the previous high intensity for speed and acceleration (positive and negative), but a strong influence can be noted for the high intensity Metabolic Power. Specifically, in relation to the shot, this study seems to add something: as recently demonstrated [25], the SSG with Goal Keeper, showed a low average intensity, especially for the metabolic power. According to this latter and considering our findings, we suggest that in the shots on goal training one should take into account the specific demands of this crucial skill (table II), that in the real game seems to be influenced, up to a certain degree, by the high intensity activities, preceding the performance.

Dribbling did not show clear information: it seems that the success could depend on other factors as well as the passes that were not depending from any high intensity form.

The interceptions and tackles seem to be purely technical events detached from the physical performance.

In relation to the frequencies of events prior to each technical skill (2), it emerges that the shots on goal had more possibilities to have success with one or more high intensity positive acceleration event. Furthermore, with three high intensity activities for positive acceleration we found $100 \%$ of the event resulted in a successful outcome.

Crosses showed that one high intensity event (in any form) prior to this skill could be a discriminant factor for the success, as well as two or three high intensity events for the MP.
Transferring the concept to a practical standpoint, the role of the fitness coach should support more consistently the work of the head coach, under the technical-tactical point of view too. A good management of all the variables (spaces, times, number of players, etc.) should be provided and monitored using the relevant technology (video analysis, GPS, big data analysis).

\section{Acknowledgments}

The authors wish to thank for his precious help K-Sport \& AMISCO Pro Tracking system, Montelabbate, PU, Italy and Prozone Sport, Leeds, UK, in the person of the Eng. Mirko Marcolini.

The authors certify that there is no conflict of interest with any financial organization regarding the material discussed in the manuscript.

The authors certify that there are no professional relationships with companies or manufactures who would benefit from the results of the present study and that the results of the present study do not constitute endorsement of the product by the authors.

\section{References}

[1] Sarmento H, Marcelino U, Hanguera MT, Campanico J, Matos N, Leitao JC Match analysis in football: a systematic review. Journal of Sports Sciences. 2014; 32(20): 1831-1843.

[2] Di Salvo V., Baron R., Tschan H., Calderon Montero FJ, Bachl N., Pigozzi F. Performance characteristics according to playing position in Elite Soccer, International Journal of Sports Medicine; 2007; 28, 222-227.

[3] Di Salvo V., Gregson W., Atkinson, Tordoff P., Drust B. Analysis of high intensity activities in Premier League Soccer, International Journal of Sports Medicine. 2009; 30, 205-212.

[4] Andrzejewski M., Chimura J., Pluta B., Strzelczyk R., Kasprzak A. Analysis of sprinting activities of professional soccer players, Journal of Strength \& Conditioning Research. 2014; 27(8), 2134-2140.

[5] Dwyer DB, Gabbett TJ. Global positioning system data analysis: Velocity ranges and a new definition of sprinting for field sport athletes, Journal of Strength and Conditioning Research. 2012; 26(3), 818-824.

[6] di Prampero PE, Fusi S., Sepulcri L., Morin J. B., Belli A., Antonutto G. Sprint running: a new energetic approach, Journal of Experimental Biology. 2005; 208, 2809- 2816.

[7] Osgnach C, Poser S, Bernardini R, Rinaldo R, di Prampero PE (2010), Energy cost and Metabolic Power in Elite Soccer: a new match analysis approach. Medicine Sciences and Sports Exercise; 42, 1:170-178.

[8] Vigne G., Dellal A., Gaudino C., Chamari K., Rogowski I., Alloatti G., Del Wong P., Owen A., Hautier C. Physical outcome in a successful Italian serie A soccer team over three consecutive season, Journal of Strength \& Conditioning Research. 2013; 27(5), 1400-1406. 
[9] Lago-Penas C., Lago-Ballesteros J., Dellal A., Gomez M. Game-related statistics that discriminated winning, drawing and losing teams from the Spanish soccer league, Journal of Sport Sciences \& Medicine. 2010; 9, 288-293.

[10] Bradley PS, Lago-Penas C., Rey E., Gomez Diaz A. The effect of high and low percentage ball possession on physical and technical profiles in English FA Premier League soccer matches, Journal of Sport Sciences. 2013; 31(12), 1261-1270.

[11] Stephenie C. Lemon Ph. D., Jason Roy Ph. D., Melissa A. Clark Ph. D., Peter D. Friedmann M. D., M. P. H., William Rakowski Ph. D. Classification and regression tree analysis in public health: Methodological review and comparison with logistic regression. Annals of Behavioral Medicine. 2003; Volume 26, Issue 3, pp 172-181.

[12] Gordon Kass V. An exploratory technique for investigating large quantities of categorical data. Applied Statistics; 1980; 29, 2: 119-127.

[13] Vilar L, Duarte R, Silva P, Jia Yi Chow, Davids K. The influence of pitch dimensions on performance during smallsided and conditioned soccer games. Journal of Sports Sciences. 2014; Vol. 32, No. 19, 1751-1759.

[14] Deprez D, Fransen J, Boone J, Lenoir M, Philippaerts R, Vaeyens R. Charactheristics of high level youth soccer players: variation by playing position. Journal of Sports Sciences; 2015; 33(3), 243-254.

[15] Diaz del Campo DG, Gonzalez Villora S, Garcia Lopez LM, Mitchell S. Differences in decision-making development between expert and novice invasion game players. Perceptual and Motor Skills; 2011; 112(3), 871-888.

[16] Stølen, T., Chamari, K., Castagna, C. and Wisløff, U. (2005), Physiology of Soccer: An Update. Journal of Sports Medicine; 35(6), 501-536.

[17] Stone KJ, Oliver JL. (2009), The effect of 45 minutes of soccer-specific exercise on the performance of soccer skills. International Journal of Sport Physiologist and Performance; 4, 163-175.
[18] Schaefer S. The ecological approach to cognitive motor dual tasking: findings on the effects of the expertise and age. Frontiers in Psychology; 2014; 5: 1167.

[19] Huijgen BCH., Elferink-Gemser MT., Post WJ, Visscher C. Soccer skills development in professionals. International Journal of Sports Medicine; 2009; 30, 585-591.

[20] Seif-Barghi T, Ramin Kordi MD, Hossein Memari A, AlMansournia M, Jalali-Ghomi M. The Effect of an Ecological Imagery Program on Soccer Performance of Elite Players. Asian Journal of Sports Medicine. 2012; Volume 3, (Number 2) Pages: 81-89.

[21] H Oner O, Votteler A, Schmid M, Schultz F, Roth K. Psycometric properties of the motor diagnostic in the German football talent identification and development programme. Journal of Sports Sciences. 2015; 33(2): 145-159.

[22] Tscholl P, O'Riordan D, Fuller CW, Dvorak J, Junge A. Tackle mechanisms and match characteristics in women's elite football tournaments. Journal of Sports Medicine. 2007; 41 (Suppl I), i15-i19.

[23] Ruscello B, Briotti G, Tozzo N, Partipilo F, Taraborelli M, Zeppetella A, Padulo J, D'Ottavio S. Acute effects of two different initial heart rates on testing the Repeated Sprint Ability in young soccer player. Journal of Sports Medicine and Physical Fitness. 2014.

[24] Ruscello, B, Tozzo, N, Briotti, G, Padua, E, Ponzetti, F, and D'Ottavio, S. Influence of the number of trials and the exercise to rest ratio in repeated sprint ability, with changes of direction and orientation. Journal of Strength Conditioning and Research. 2013; 27(7), 1904-1919.

[25] Gaudino P, Alberti G, Iaia FM. (2014), Estimated metabolic and mechanical demands during different small sided games in elite soccer players. Human Movement Science; 36, 123 133. 